\title{
Pandemia do Coronavírus e (des)coordenação federativa: evidências de um conflito político- territorial
}

The Covid-19 pandemic and (dis) agreement federation: evidences of a political and territorial conflict

Pandemia del covid-19 y (des) cordenación federativa: evidéncias de un conflicto político y territorial

Pandémie de la covid-19 et (dé-) coordination fédérative : évidences d'un conflit politico-territorial

Juliana Nunes Rodrigues e Daniel Abreu de Azevedo

\section{OpenEdition}

Journals

Edição electrónica

URL: http://journals.openedition.org/espacoeconomia/12282

DOI: 10.4000/espacoeconomia.12282

ISSN: 2317-7837

Editora

Núcleo de Pesquisa Espaço \& Economia

Refêrencia eletrónica

Juliana Nunes Rodrigues e Daniel Abreu de Azevedo, « Pandemia do Coronavírus e (des)coordenação federativa: evidências de um conflito político-territorial », Espaço e Economia [Online], 18 | 2020, posto online no dia 23 abril 2020, consultado o 20 maio 2020. URL : http://journals.openedition.org/ espacoeconomia/12282 ; DOI : https://doi.org/10.4000/espacoeconomia.12282

Este documento foi criado de forma automática no dia 20 maio 2020.

(C) NUPEE 


\title{
Pandemia do Coronavírus e (des)coordenação federativa: evidências de um conflito político- territorial
}

\author{
The Covid-19 pandemic and (dis) agreement federation: evidences of a political \\ and territorial conflict \\ Pandemia del covid-19 y (des) cordenación federativa: evidéncias de un conflicto \\ político y territorial \\ Pandémie de la covid-19 et (dé-) coordination fédérative : évidences d'un conflit \\ politico-territorial
}

Juliana Nunes Rodrigues e Daniel Abreu de Azevedo

\section{Introdução}

1 Diante de milhares de mortes em decorrência da difusão da pandemia de coronavírus no Brasil, a crise social que se instalou no país é algo que poucos poderiam imaginar que ocorreria, e as consequências são sentidas não apenas no combalido sistema de saúde brasileiro, mas também no cotidiano das pessoas, na economia e, de forma bastante evidente, na instauração de uma crise federativa. Nesse contexto, cientistas sociais das diversas matrizes disciplinares e teóricas têm procurado extrair reflexões a partir de seus campos de pesquisa, e é esta a modesta pretensão deste texto.

2 A partir do olhar de dois geógrafos políticos que se preocupam com os dilemas da engenharia político-institucional e territorial brasileira, procura-se contribuir para o debate sobre a complexa trama de implicações federativas que têm acompanhado a propagação territorial do vírus. Nosso objetivo é destacar que a crise da pandemia do coronavírus no Brasil expôs entraves para a articulação entre os entes federativos decorrentes da confusão de seus papeis, colocando em risco as medidas de 
enfrentamento. Trata-se, pois, de enfocar o debate sobre as relações entre as escalas decisórias que definem decisões e ações válidas para recortes político-administrativos precisos (LEVY, 1991). Pontuamos que a atuação coordenada entre os entes federativos, com destaque para a premência de ações nas escalas locais em um território profundamente desigual, é o caminho seguro para o enfrentamento da crise.

3 Pode-se dizer que o federalismo brasileiro passou por fases que se alternaram pelo maior grau de centralização ou descentralização política. Em alguns períodos, como no caso dos dois governos ditatoriais (1937-1945 e 1964-1985), o grau de centralização era tamanho que "estados e governos locais quase se transformam em agentes administrativos de um governo nacional com grande envolvimento em assuntos subnacionais, predomínio nos processos de decisão e no controle dos recursos financeiros" (ALMEIDA, 2005, p.31). Porém, dado o fim da ditadura militar na década de 1980, o progressivo processo de descentralização foi posto em marcha como um modo de democratizar o sistema político brasileiro. Não vamos aqui nos ater aos equívocos já largamente explorados acerca das leituras apressadas que aproximam descentralização e democracia ${ }^{1}$. No entanto, foi efetivamente com a promulgação da Carta Magna de 1988 que o Brasil experimentou uma nova onda de valorização das escalas subnacionais, a qual garantiu aos municípios a posição de ente federativo. Importa destacar que esse status não é conferido às estruturas de gestão local em nenhum outro Estado federal, ainda que o processo de descentralização, no Brasil, não tenha se completado - as efetivas capacidades administrativa, financeira e a autonomia política nessas escalas são profundamente afetadas por constrangimentos de diversas ordens, inclusive constitucionais, como se verá mais adiante. Somem-se a esses constrangimentos mediações demográficas, políticas, econômicas e territoriais, marcas das desigualdades que se expressam nas múltiplas escalas e recortes subnacionais do País.

4 São justamente a fragilidade e as contradições dessa relativa descentralização política que a crise político-institucional do coronavírus expõe de forma cristalina. Desde o processo de redemocratização do Brasil na década de 1980, novas competências foram atribuídas ao Município. Com efeito, a nova Constituição confere uma gama de novas responsabilidades, que vão desde criar divisões distritais até a responsabilidade sobre a definição de políticas de educação, de saúde, de saneamento básico e de mobilidade, entre outras (ABRUCIO, 1998). No entanto, as capacidades financeiras não acompanharam esse processo de incremento de atribuições, e permaneceram bastante concentradas na União, gerando-se contradições de difícil solução; isto é, houve a obrigação constitucional de um leque de atribuições, mas sem, necessariamente, que ficassem garantidos recursos necessários para executá-las. Isso explica a forte dependência dos municípios em relação às transferências (constitucionais ou não) da União e dos estados aos seus orçamentos (RODRIGUES, 2006).

5 Indo mais além, a Constituição de 1988 estabeleceu um conjunto de competências compartilhadas entre as três escalas decisórias - a saber, União, estados e municípios -, notadamente nos setores mais fundamentais das políticas sociais, como os de saúde, de educação e de assistência social. Entretanto, a concorrência de atribuições nesses setores, pouco claro na letra da lei e propenso a barganhas federativas - foi frequentemente caracterizado por sobreposições, incoerências e - o que é ainda pior -, lacunas significativas na oferta de bens e serviços públicos os mais essenciais. Acrescente-se que o desenho político-institucional firmado em 1988 possibilitou que, 
por meio da aprovação de emendas parlamentares, uma progressiva recentralização do papel da União tenha ocorrido ao longo dos anos (ARRETCHE, 2012).

6 Em síntese, está-se diante de um problema de coordenação político-territorial que se manifesta em três dimensões políticas: i) na dimensão institucional e da ordem do sistema político que, no Brasil, caracteriza-se por um pacto federativo bastante centralizado e pouco claro na definição dos limites de competências; ii) nos conflitos político-partidários que afetam a governabilidade e a governança do sistema; e iii) no desenho das ações e nas escolhas políticas adotadas. Há, portanto, uma constante tensão político-institucional que resulta em arranjos e acomodações para a gestão de conflitos.

7 Diante da proliferação do vírus, essas tensões se exacerbam em uma permanente e inconsequente politização da saúde pública - assiste-se a um despudorado cenário em que governadores, prefeitos e governo federal se valem das falhas e oportunidades facultadas pelo desenho político-institucional para arriscarem suas apostas. Para fins de contribuição com o debate público, buscamos sintetizar alguns dos gargalos que dificultam a gestão territorial da crise.

\section{0 avanço do vírus expõe nossos problemas político- institucionais}

8 Se recuperarmos algumas reportagens divulgadas no último mês sobre as dificuldades para enfrentamento da crise, percebemos que um dos grandes entraves para um combate eficaz está a falta de clareza sobre as atribuições de cada escala decisória e a falta de coordenação federativa. Desde o começo do governo, o presidente Jair Bolsonaro tem mantido notável distanciamento dos governadores, além de ter gerado conflitos com alguns deles, discriminando grupos regionais supostamente opositores e/ ou concorrentes. Os governadores, por outro lado, escreveram cartas públicas, criaram consórcios regionais, escolheram porta-vozes, e têm intensificado, publicamente, menções a adversidades e mesmo feito declarações de repúdio a pronunciamentos do Presidente da República. Temos, assistido, portanto, semana após semana, à elevação da temperatura entre prefeitos, governadores e presidente em relação às ações de enfrentamento à pandemia em território nacional ${ }^{2}$.

9 Para exemplificar, em reportagem do dia 25 de março de 2020, o jornal $O$ Globo questionou qual representante do Poder Executivo teria a atribuição constitucional de mandar reabrir o comércio durante a pandemia de coronavírus no município do Rio de Janeiro - se Jair Bolsonaro, Wilson Witzel ou Marcelo Crivella, respectivamente Presidente da República, Governador de estado e Prefeito. A jornalista que a subscreve apontou que na mesma data em que o Presidente da República concedeu uma declaração contra decretos estaduais em prol das medidas de isolamento e do fechamento do comércio, o prefeito do Rio permitiu a sua reabertura, mas, logo em seguida, o governador interveio e a revogou. $O$ caos político-institucional se instalou e a população não sabia não apenas a qual autoridade seguir, mas, tampouco, a qual instância caberia o poder de decisão. A reportagem afirma:

A Carta não é clara sobre os papéis da União, dos estados e dos municípios. 0 artigo $30 \mathrm{diz}$ que compete aos municípios "legislar sobre assuntos de interesse local" - o que, na prática, é bastante amplo. 0 artigo 25, que os estados têm "as competências que não lhes sejam vedadas pela Constituição”. E o artigo 21 dá à União a atribuição 
de "planejar e promover a defesa permanente contra as calamidades públicas, especialmente as secas e as inundações. muitas das competências citadas no artigo 23 na forma de competências compartilhadas; ou seja, espera-se que os municípios assumam responsabilidades sobre as políticas públicas de proximidade (RODRIGUES e MOSCARELLI, 2016). No entanto, na ausência de atuação local, os estados e a União podem intervir nas atribuições citadas no artigo 23 na forma de "gestão compartilhada". Ademais, a Constituição manteve a tradição de concentrar grande parte da capacidade de legislar na escala federal, o que limitou a autonomia dos governos de estados e municípios para se lançarem em iniciativas próprias (ABRUCIO; SOARES, 2001; SOUZA, 2003).

11 Na semana anterior, a contenda girou em torno do fechamento de aeroportos e de estradas, visto que muitos governadores intentavam isolar seus respectivos estados e impedir a circulação de pessoas oriundas de locais com alto nível de contágio. A reportagem do $\mathrm{Uol}^{4}$ do dia 20 de março de 2020 informou que "a Bahia foi à Justiça para conseguir fazer uma barreira sanitária de viajantes de São Paulo e Rio, o Maranhão também vai entrar com ação judicial e Goiás pretende fechar aeroportos". Antes disso, o governador fluminense já havia determinado o fechamento das divisas do estado e o presidente Jair Bolsonaro teria afirmado que não caberia aos governos estaduais essa decisão, mas sim à União a partir das agências, como a ANTT (Agência Nacional de Transportes Terrestres, no caso de transporte interestadual de ônibus) e da ANAC (Agência Nacional de Aviação Civil, para o transporte aeroviário). Em nota divulgada pela ANAC, o órgão respondeu ao governador do Rio de Janeiro da seguinte maneira:

Segundo a Constituição Federal, aeroportos são bens públicos da União Federal, atendendo a interesse de toda a nação, além das localidades imediatamente servidas. Visando o interesse público, cabe à União determinar o fechamento de aeroportos e de fronteiras. No que diz respeito a questões fitossanitárias, esta determinação segue as orientações do Ministério da Saúde e da Agência Nacional de Vigilância Sanitária (Anvisa).

O conflito em torno do fechamento do comércio, de estradas e de aeroportos chegou à instância do Supremo Tribunal Federal, cuja decisão tomada por dois ministros em caráter liminar determinou que, para o caso de bares, restaurantes e outros tipos de estabelecimentos comerciais, não restaria dúvida de que a decisão sobre o fechamento ou a abertura caberia aos governos locais, e não ao Governo Federal. Por outro lado, "Marco Aurélio Mello decidiu na terça-feira que não apenas a União, mas estados e municípios também têm poderes para definir a locomoção por estradas, portos e aeroportos - seja em surto de coronavírus ou não" (o Globo, 25/03/2020).

Na região metropolitana do Rio de Janeiro, em Niterói, o prefeito decidiu, desde o dia 4 de abril, restringir o acesso ao município. Criaram-se então 28 pontos de bloqueio, que incluíram a construção de barricadas de concreto para impedir a passagem de ônibus e carros provenientes de municípios vizinhos. Ao site $R 7$ Notícias ${ }^{5}$, o secretário municipal de Urbanismo e Mobilidade de Niterói afirmou que

O trânsito será totalmente bloqueado em 21 ruas e estradas vicinais da cidade que se conectam com Maricá e São Gonçalo. Nesse primeiro momento, nos sete pontos possíveis de acesso a Niterói será feito o controle de entrada de veículos, e os táxis de outras cidades serão orientados a voltar daquele ponto, pois não poderão mais entrar na cidade a partir do sábado. 

a cargo de legislações complementares, que até o presente não foram regulamentadas a contento para diversos setores de políticas públicas. Ou seja, efetivamente, a assunção de responsabilidades sobre um conjunto de políticas públicas pode se alterar ao sabor de um jogo político muitas vezes circunstancial, em que pesam o ônus ou os retornos políticos que a aceitação de determinada responsabilidade pode significar para cada governante. Ou ainda, conforme demonstrou cuidadosamente Marta Arretche em sua pesquisa sobre os condicionantes da descentralização de políticas sociais no Brasil, a assunção de responsabilidade sobre políticas não claramente definidas pela Constituição é resultado ora da iniciativa própria de cada ente federado, ora de incentivos e estímulos à adesão a algum programa proposto por uma escala de governo (ARRETCHE, 2000).

19 Nesse quadro, as prefeituras têm autonomia para assumir ou não determinados serviços, assim como para aderir a programas ou políticas adotadas pelos estados e pelo Governo Federal. Em suma, quaisquer discussões acerca de políticas públicas compartilhadas entre escalas de poder político têm necessariamente como ponto de partida negociações e acordos que se dão em arenas políticas distintas. No contexto

No entanto, as diretrizes sobre como a coordenação de decisões e ações deve se estabelecer, assim como os diferentes papéis dos entes federativos na "partilha" partida negociaçoes e acordos que se dão em arenas politicas distintas. No contexto 
atual, a competição político-eleitoral precoce parece orientar os discursos, as decisões e ações políticas mais do que a propalada "cooperação federativa".

É esse embate e problema político-institucional que a pandemia de coronavírus ilumina. Em se tratando da política pública de saúde, de grande impacto orçamentário, a concentração de recursos na União dificulta a autonomia do município para atuar de modo eficaz no combate à pandemia e em outros setores públicos correlacionados.

21 Segundo levantamento de dados da Frente Nacional de Prefeitos, entre 2002 a 2018 houve um decréscimo de participação da União no aporte financeiro para custear a saúde, mesmo sendo esse o ente federativo que detêm mais da metade de todos os recursos públicos do País. O quadro abaixo revela que a União era responsável por $52,4 \%$ em 2002, e em 2018 esse número caiu para 43,9\%, o que aumentou a pressão nos municípios para investimento nesse setor de política pública.

Quadro 1. Despesa de cada ente federado com ações e serviços públicos de saúde

\begin{tabular}{|l|l|l|l|}
\hline Ano & União & Estados & Municípios \\
\hline 2002 & $52,4 \%$ & $22,1 \%$ & $25,5 \%$ \\
\hline 2003 & $50,5 \%$ & $24 \%$ & $25,6 \%$ \\
\hline 2004 & $49,3 \%$ & $26 \%$ & $24,7 \%$ \\
\hline 2005 & $48,2 \%$ & $25,5 \%$ & $26,3 \%$ \\
\hline 2006 & $46,7 \%$ & $26,3 \%$ & $27 \%$ \\
\hline 2007 & $45,8 \%$ & $26,9 \%$ & $27,3 \%$ \\
\hline 2008 & $43,4 \%$ & $27,6 \%$ & $29 \%$ \\
\hline 2009 & $46,6 \%$ & $25,8 \%$ & $27,6 \%$ \\
\hline 2010 & $44,7 \%$ & $26,9 \%$ & $28,4 \%$ \\
\hline 2011 & $45,3 \%$ & $26 \%$ & $28,8 \%$ \\
\hline 2012 & $45,3 \%$ & $25,3 \%$ & $29,4 \%$ \\
\hline 2013 & $42,6 \%$ & $26,7 \%$ & $30,7 \%$ \\
\hline 2014 & $42,4 \%$ & $26,5 \%$ & $31,1 \%$ \\
\hline 2015 & $43 \%$ & $26 \%$ & $31 \%$ \\
\hline 2016 & $42,8 \%$ & $25,5 \%$ & $31,6 \%$ \\
\hline 2017 & $43,2 \%$ & $25,7 \%$ & $31,3 \%$ \\
\hline 2018 & $43,9 \%$ & $24,9 \%$ & $31,2 \%$ \\
\hline
\end{tabular}

Fonte: FMP 9 
Sobre esse quadro, o presidente da Associação Mineira de Municípios afirmou em entrevista que "a gente vive em uma federação capenga, às avessas. Isso porque o dinheiro está todo concentrado nas mãos de quem não presta serviço, que é a União. Enquanto a gente, município que presta o serviço, que tem maior contato com a população e sabe onde está precisando mais, não tem o dinheiro" ${ }^{10}$.

O quadro acima expõe, porém, que o padrão de alocação de recursos está orientado de forma a destacar o papel de regulação que a União deve desempenhar no nosso desenho federativo atual. A mais ampla capacidade de gasto da União significa que é essa a escala que conta com "recursos institucionais para coordenar as ações dos governos subnacionais em torno de objetivos comuns" (ARRECTCHE, 2012, p.22).

Sobre o grau de centralização e descentralização de recursos, que compreendem inclusive vinculações e condicionalidades constitucionais que orientam transferências e reafirmam papel redistributivo da União, diversas proposições e agendas de reformas são postas em debate ${ }^{11}$. No entanto, definir em qual escala, como e onde executar as políticas públicas e clarificar os marcos regulatórios dos limites de atribuições entre os entes federativos não é uma tarefa trivial. Talvez os modos de enfrentamento da crise consolidem, porém, uma oportunidade para enfrentá-la.

\section{Nós vivemos no município, mas quem deve coordenar as ações é a União}

A declaração do presidente da Associação Mineira de Municípios, se lida de forma apressada, poderia nos levar a alegar que caberia ao Município, como escala de proximidade, o papel de traçar estratégias para enfrentamento da crise. Trata-se de uma "meia" verdade, pois é efetivamente no município que todos habitamos e exercemos direitos e deveres, é onde votamos e onde candidatos são votados; e é nele que são acessadas as políticas públicas mais relacionadas às características socioterritoriais particulares de onde vivemos (CASTRO, 2005).

No entanto, é oportuno acrescentarmos ao debate uma precisão conceitual, bastante cara a análises sobre nosso pacto federativo - entre as escalas do policy making e aquela do policy decision making (ARRETCHE, 2012). Essa distinção analítica se refere à capacidade de decidir sobre a forma de implementar (policy making) e à capacidade de regular e de coordenar as decisões (policy decision making). A partir dessa discriminação, entende-se que, em se tratando de políticas sociais que se quer universalizadas em território nacional, o papel da União de regulação e de coordenação de ações é indelegável. Isso quer dizer, por um lado, que na escala federal se detém a capacidade de policy decision making, devendo-se definir os princípios, desenhar as políticas e programas de ação, as metas, além de, por meio da maior capacidade de gasto, supervisionar as ações a serem implementadas. Por outro lado, no que se refere à capacidade decisória sobre as estratégias e ações de enfrentamento de proximidade, as responsabilidades se voltam para as escalas subnacionais. Desse modo, a regulação federal afeta decisivamente as agendas dos governos subnacionais. Porém, na fase de implementação, há margens de discordâncias que interferem no desempenho das políticas (ARRETCHE, 2012, p.24). Sobre isso, Arretche afirma que:

Ainda que os poderes regulatórios da União exerçam forte influência sobre a agenda

e as políticas das unidades constituintes, seria equivocado concluir que as unidades 
constituintes não são atores relevantes na formulação e implementação de políticas

públicas (ARRETCHE, 2012, p. 22).

27 As escalas de atuação política são, portanto, complementares. É na escala do cotidiano, em que gestores e agentes públicos se deparam com as particularidades de seus espaços de adensamento e de complexidades intraurbanas, que encontramos condições a serem valorizadas para o enfrentamento da pandemia. O espaço intraurbano, com todas as suas particularidades sociodemográficas, é de maior conhecimento pelos gestores municipais, na sua capacidade de identificação de áreas com maiores chances de contágio em relação às suas diferenças de adensamento, às condições de saneamento básico, de moradia e, sobretudo, em relação às suas capacidades de atendimento em saúde instaladas. Além disso, prefeitos e vereadores possuem conexões com líderes de associações de moradores e outros movimentos sociais e agentes urbanos passíveis de apoiar ações, inclusive no que se refere à comunicação e ao acesso à própria população. Acrescentem-se as modalidades de cooperações intermunicipais entre entes federativos, como os Consórcios Intermunicipais (RODRIGUES, 2011; 2010) e os espaços políticos municipais representativos, como a ideia dos Conselhos Municipais (AZEVEDO, 2018), que poderiam ser mais bem mobilizados como instrumentos e canais para a elaboração de estratégias voltadas para a ampliação de políticas de saneamento, da rede de prevenção, do atendimento básico em saúde e, também, de combate a epidemias.

Por fim, diante dos acontecimentos e da gravidade da crise federativa instalada, são patentes a descoordenação no próprio âmbito federal e a inapetência do Governo Federal para unificar os princípios que devem nortear as ações nas escalas subnacionais. A tônica tem sido, pelo contrário, a incongruência de discursos e de ações. Esse quadro se agrava de forma ainda mais dramática se consideramos o problema da (des) coordenação em uma sociedade e em um território extremamente complexos e desiguais.

Em síntese, se a difusão do coronavírus expõe números e estatísticas que caracterizam um fenômeno de disseminação global, é nos marcos das contradições e das fragilidades políticas e institucionais da Federação e dos governos brasileiros que vivenciamos o enfrentamento da pandemia. Nesse quadro, as lacunas do nosso pacto federativo, associadas aos conflitos de interesses político-partidários que se ancoram em diferentes escalas de poder, parecem nublar os processos de tomada de decisões e de ações republicanas para o enfrentamento do vírus.

BIBLIOGRAFIA

ABRUCIO, F. Os Barões da Federação: os governadores e a redemocratização brasileira. São Paulo: Hucitec/USP, 1998.

ABRUCIO, F. L.; SOARES, M. M. Redes federativas no Brasil: cooperação intermunicipal no Grande ABC. São Paulo: Fundação Konrad Adenauer, Série Pesquisas, n. 24, 2001. 
ALMEIDA, M. H. T. Recentralização a federação? Revista de Sociologia Política, Curitiba, 24, p.29-40, jun-2005.

ARRETCHE, Marta. Estado Federativo e Políticas Sociais:determinantes da descentralização. Rio de Janeiro: Revan. São Paulo: FAPESP, 2000.

ARRETCHE, Marta. Democracia, Federalismo e Centralização no Brasil. Rio de Janeiro: FGV Editora. Editora Fiocruz, 2012.

AZEVEDO, Daniel Abreu. Modelos de democracia e espaços políticos: o caso da democracia participativa. Revista Geografares, v.15, n.1, 2018, p.126-146.

CASTRO, Iná Elias. Geografia e política: territórios, escalas de ação e instituições. Rio de Janeiro: Bertrand Brasil, 2005.

LEVY, J. (Dir.). Géographies du politique. Paris: Presses de la Fondation Nationale des Sciences Politiques et Espaces Temps, 1991.

RODRIGUES, J. N. As Transferências Intergovernamentais de Recursos do FPM e do ICMS como Estratégia de Equilíbrio Sócio-Espacial. Dissertação de Mestrado. Universidade Federal do Rio de Janeiro/ Programa de Pós-Graduação em Geografia. Rio de Janeiro, 2006.

RODRIGUES, J. N. La coopération intercommunale, regards croisés entre la France et le Brésil. (Tese de Doutorado) Doutorado em Geografia, Université Jean Moulin Lyon III, Lyon, 2010.

RODRIGUES, J. N. Cooperação Intermunicipal na França e no Brasil em Perspectiva Comparada. Mercator, Fortaleza, v. 10, n. 23, p.23-31, set./dez. 2011.

RODRIGUES, J.N. e MOSCARELLI, F. Os desafios do pacto federativo e da gestão territorial compartilhada na condução das políticas públicas brasileiras. GeoTextos, vol. 11, n. 1, julho 2015.

SOUZA, C. Regiões Metropolitanas: Condicionantes do Regime Político. Lua Nova. Revista de Cultura e Política. São Paulo, v. 59, p. 137-158, 2003.

\section{NOTAS}

1. Sobre isso, ver Rodrigues, 2010.

2. Para uma breve síntese, ver Miriam Leitão, Política de Governadores, Jornal o Globo, 26/03/2020.

3. Retirado da página https://oglobo.globo.com/analitico/bolsonaro-witzel-ou-crivella-quempode-mandar-reabrir-comercio-durante-pandemia-de-coronavirus-24327828 no dia 09 de abril de 2020.

4. Extraído da página https://www1.folha.uol.com.br/equilibrioesaude/2020/03/fechamento-deestradas-preocupa-governo-e-auxiliares-pedem-que-bolsonaro-planeje-acoes-comgovernadores.shtml?origin=folha no dia 09 de abril de 2020.

5. Retirado da página https://noticias.r7.com/rio-de-janeiro/com-28-pontos-de-bloqueioniteroi-restringe-acesso-ao-municipio-04042020 no dia 09 de abril de 2020.

6. Conforme reportagem da Folha de São Paulo publicada no dia 11/04/2020. Acessível em: https://www1.folha.uol.com.br/equilibrioesaude/2020/04/bolsonaro-desmobiliza-combate-aonovo-coronavirus-diz-prefeito-de-manaus.shtml, em16 de abril de 2020.

7. Folha de São Paulo, 15/04/2020. Acessível em: https://www1.folha.uol.com.br/poder/2020/04/ com-recados-a-bolsonaro-stf-forma-maioria-para-permitir-estados-a-regulamentaremisolamento-social.shtml. Data de acesso: 16/04/2020. 
8. Ministro Alexandre de Moraes em seu discurso de fundamentação do voto que referendou a decisão do Ministro Marco Aurélio Melo do dia 24 de março de 2020. Cf. Reportagem da Folha de São Paulo indicada acima.

9. Retirado da página https://www.otempo.com.br/politica/subscription-required-7.5927739? aId=1.2257412 no dia 09 de abril de 2020 .

10. Retirado da página https://www.conjur.com.br/2018-abr-25/cesar-caula-dru-concentracaorecursos-poder-uniao no dia 09 de abril de 2020

11. A PEC 188/2019, denominada "PEC do Pacto Federativo", proposta pelo atual governo, estabelece diretrizes para promover uma maior descentralização e desvinculação de gastos. Porém, o texto possui incoerências e imprecisões internas, sendo bastante controverso em seu conteúdo.

\section{RESUMOS}

Após quatro meses desde o primeiro caso do novo coronavírus (COVID-19) detectado no Brasil, governos municipais, estaduais e a União ainda travam embates sobre as responsabilidades de cada ente da federação na busca de soluções para o maior problema sanitário do século XXI. Este artigo tem como objetivo destacar os entraves político-institucionais existentes em nosso Pacto Federativo, ancorados no funcionamento do federalismo cooperativo brasileiro. Argumenta-se que um combate eficaz à pandemia se faz, necessariamente, pela articulação entre os entes federativos norteada pela União, com planos de atuação e de implementação definidos pelos gestores nas escalas locais.

Four months later the first case of the new coronavirus (COVID-19) detected in Brazil, the three levels of government (municipal, state and federal powers) are in open conflict concerning its responsibility to solve the biggest health problem of the 21st century. In this way, this article aims to reveal how the political-institutional barriers of the Federative Pact are directly linked to the Brazilian cooperative federalism. To solve the crisis, we stress the need for coordination between federal entities pivoted by Union, but so the plans of action as the ways to put in practice them should be defined by governors at the local level.

Después de cuatro meses desde el primer caso del nuevo coronavirus (COVID-19) detectado en Brasil, los gobiernos municipales, estatales y federales todavía están en afrontamiento por las responsabilidades de cada entidad de la federación en la búsqueda de soluciones para el mayor problema de salud del siglo XXI. Este artículo tiene como objetivo revelar las barreras políticas e institucionales que existen en nuestro Pacto Federativo, cuyas consecuencias se sienten directamente en el funcionamiento del federalismo cooperativo brasileño. Se argumentará que una lucha efectiva contra la pandemia se hace, necesariamente, por la articulación entre las entidades federales promovidas por la Unión, pero los planes de acción y las formas de implementarlos deben de ser dirigidos por el Municipio.

Quatre mois après le premier cas du nouveau coronavirus (COVID-19) au Brésil, les municipes, les états fédérés et le Gouvernement Fédéral se débattent sur les responsabilités de chaque échelon pour la mise en oeuvre d'actions pour faire face au problème sanitaire le plus grave du 21e siècle. Cet article vise à mettre en lumière des éléments du cadre politico-institutionnel brésilien qui rendent difficile la coordination fédérative pour gérer la diffusion territoriale du virus. Or, on 
affirme que des actions efficaces contre la pandémie comprennent nécessairement la coordination entre les échelons de pouvoir, orientées par l'Union, mais comptant sur des plans d'action et des modalités d'intervention aux échelles locales.

\section{ÍNDICE}

Mots-clés: Pacte Fédératif, COVID-19, coronavirus, fédéralisme coopératif, Brésil.

Palabras claves: pacto federativo, COVID-19, coronavirus, federalismo cooperativo, Brasil. Keywords: federative pact, COVID-19, coronavirus, cooperative federalism, Brazil.

Palavras-chave: pacto federativo, COVID-19, coronavírus, federalismo cooperativo, Brasil.

\section{AUTORES}

\section{JULIANA NUNES RODRIGUES}

Professora do Departamento de Geografia e do Programa de Pós-Graduação em Geografia da Universidade Federal Fluminense. Doutora em Geografia pela Université Jean Moulin Lyon 3, França, tendo realizado estágio em pesquisa no Instituto de Sciences-Po, Paris. Desenvolve pesquisas na área de Geografia Política, com ênfase nos seguintes temas: federalismo brasileiro e território, escalas políticas, políticas públicas, participação política, governança e cooperação territorial. É coordenadora do Núcleo de Pesquisas sobre Pactos Político-Territoriais e Desenvolvimento (www.nupact.com.br). E-mail: juliananunes@id.uff.br

\section{DANIEL ABREU DE AZEVEDO}

$\mathrm{O}$ autor trabalha desde sua tese de doutorado com a relação entre espaço político e democracia, com especial interesse na América Latina. Tem estágio em doutorado no Centro de Estudos sobre América Latina da American University (Washington D.C.) e pós-doutorado na Universidad Nacional Autónoma de México. Atualmente é Professor Adjunto do Departamento de Geografia da Universidade de Brasília, onde desenvolve pesquisas que lidam com a estrutura políticoterritorial brasileira e a democracia. Suas pesquisas buscam conciliar a Geografia Política e reflexões metodológicas quantitativas e qualitativas. É vinculado ao Grupo de Estudos e Pesquisas sobre Política e Território (GEOPPOL-UFRJ). Email: dan_abreudeazevedo@hotmail.com 